Molecules 2004, 9, 22-28

\title{
molecules
}

ISSN 1420-3049

http://www.mdpi.org

\section{Addition of Organochromium Reagents to Heteroaryl Aldehydes. Synthesis of Heteroaryl Substituted bis-Allyl Ethers and Homoallyl Ethers}

\section{S. Servi * and C. Topaloglu}

Department of Chemistry, Firat University, Faculty of Science and Arts, 23169, Elazig, Turkey.

Author to whom correspondence should be addressed; e-mail: sservi@firat.edu.tr

Received: 25 September 2003; in revised form: 9 January 2004 /Accepted: 19 January 2004 /

Published: 31 January 2004

\begin{abstract}
Heteroaryl substituted allyl and homoallyl alcohols were synthesised with two different method. Synthesis of bis-allyl ethers and homoallyl ethers were carried out via reaction of allyl bromide with allyl alcohols and homoallyl alcohols, respectively. [2.3]-Wittig Rearrangement reactions of heteroaryl substituted bis-allyl ethers were investigated using GC/MS techniques. In these reactions two unexpected products were isolated in high yield.
\end{abstract}

Keywords: Nozaki-Hiyama reaction, Organochromium reagents, Heteroaromatic aldehydes

\section{Introduction}

A selective carbon-carbon bond forming reaction was described by Nozaki-Hiyama in 1977 based on the mild addition of alkenyl, alkynyl or vinyl chromium (III) compounds to aldehydes in an anhydrous medium. The Nozaki-Hiyama reaction is mainly applied to aldehydes but ketones can be used in some cases and the reaction can be also extended to other organochromium reagents. This reaction has been widely employed in natural product synthesis, becoming the key step in some synthesis plans and it played a key role, for example, in the highly stereocontrolled synthesis of the aliphatic segment of the antibiotic rifamycin $S$ [1-5].

The [2,3]-Wittig Rearrangement of unsymmetrical bis-allylic ethers is exceedingly useful for regio- and stereoselective preparations of substituted allyl alcohols. This reaction has also 
attracted the interest of chemists as the subject of mechanistic investigations and has been increasingly utilized as a useful methodology for organic synthesis [6-10].

This article reports the synthesis of heteroaryl substituted allyl and homoallyl alcohols and their ethers. Also reported are synthesis of heteroaryl substituted bis-allyl ethers and their [2,3]Wittig Rearrangement reactions. In this reaction, two unexpected products were isolated in high yields. These compounds were characterized by using ${ }^{1} \mathrm{H}-\mathrm{NMR}$, FT-IR and GC/ MS techniques.

\section{Results and Discussion}

There are several methods for the preparation the substituted allyl and homoallyl alcohols [1113]. In this study, heteroaryl substituted allyl and homoallyl alcohols were synthesized using the Nozaki-Hiyama reaction. This reaction was carried out with both commercial $\mathrm{CrCl}_{2} / \mathrm{DMF}$ (Method A) and $\mathrm{CrCl}_{3} / \mathrm{LiAlH}_{4} / \mathrm{THF}$ (Method B). The reaction was performed at $25{ }^{\circ} \mathrm{C}$ in DMF for Method A, and the reaction was relatively fast with high yields compared with Method B.

Chromium (II) chloride is a powerful reducing agent. Anhydrous chromium (II) chloride is commercially available and can be used without further purification. A suitable chromium (II) reagent is prepared by reduction of 2 equivalents of anhydrous $\mathrm{CrCl}_{3}$ with one equivalent of $\mathrm{LiAlH}_{4}$ in THF at $0{ }^{\circ} \mathrm{C}$, Method B.

\section{Scheme 1}
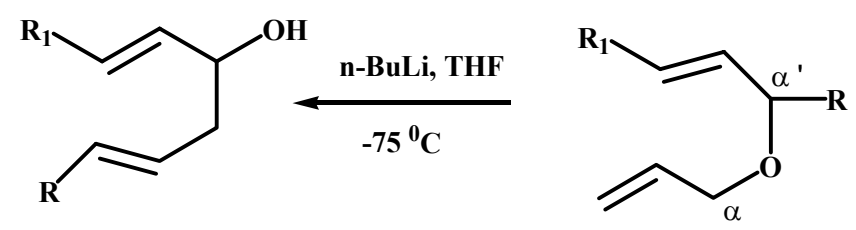

5,6

$\alpha$-lithiation products $\mathrm{R}_{1}=\mathrm{CH}_{3}$ or phenyl $\mathrm{R}=\mathrm{H}$ $\begin{array}{ll}\text { R: Furan for } 5,9 & \mathrm{R}_{1}=\mathrm{H} \\ \text { R: Thiophene for } 6,10 & \mathrm{R}_{1}=\mathrm{H}\end{array}$

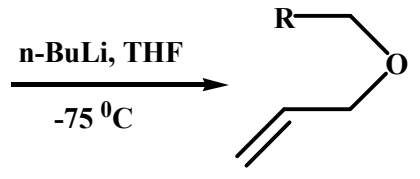

9,10

unexpected compounds

The [2.3]-Wittig Rearrangement reactions of 2-(1-allyloxy allyl) furan (5) and 2-(1allyloxy allyl) thiophene (6) were carried out according to published procedures [6-10]. In all of the rearrangements of unsymmetrical substrates with different substitution patterns at the $\alpha$ - and $\alpha$ ' positions of the two allylic moieties, lithiation takes place exclusively on the less substituted allylic moiety, thus leading to the exclusive formation of the [2,3]-Wittig product as a single regioisomer as shown Scheme 1.

In this work, instead of the expected products of $\alpha$-lithiation, compounds $\mathbf{9}$ and $\mathbf{1 0}$ were produced in the $[2,3]$-Wittig rearrangement reaction. $\alpha$-Lithiation products have been obtained when in compounds 5, $6 \mathrm{R}_{1}=\mathrm{CH}_{3}$ and phenyl and $\mathrm{R}=\mathrm{H}$ [6]. On the other hand, the unexpected compounds were isolated when in compounds $5,6 \mathrm{R}=$ thiophene and furan, $\mathrm{R}_{1}=\mathrm{H}$. We are not able to suggest a reaction mechanism for to account for compounds $\mathbf{9}$ and $\mathbf{1 0}$. The MS spectra of compounds 9, 10 are explained in detail in Schemes 2, 3. 


\section{Scheme 2}

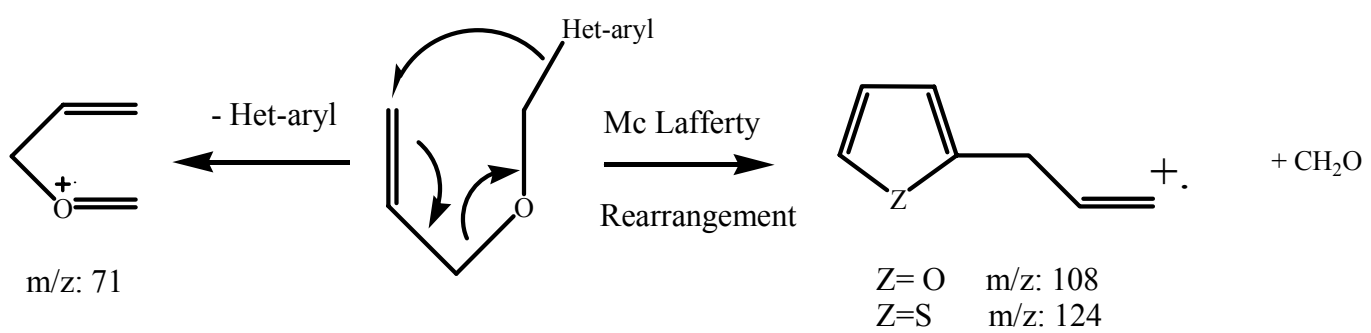

$\alpha$-Cleavage is reduced to a secondary process, as demonstrated by the low abundance of a $\mathrm{m} / \mathrm{e}$ 71 peak in the mass spectra of compounds 9, 10 (Scheme 2). Similarly, $\alpha$-fission followed by olefin elimination is essentially absent. Instead, rupture of the carbon-oxygen linkage with charge retention on the hydrocarbon moiety (m/e 41$)$ becomes dominant. In allyl alkyl ethers, carbonoxygen bond cleavage yielding allylic ions are the most important fragmentation process. Instead, a series of peaks of medium intensity at even mass numbers is observed whose genesis requires rearrangement processes, but the paucity of experimental data makes structural assignments very tentative [14].

Scheme 3

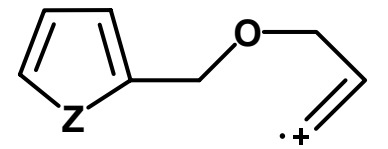

Molecular ion peaks for 9,10

$\mathrm{Z}=\mathrm{O} \quad \mathrm{M}^{+} \cdot 138 \mathrm{gmol}^{-1}\left(\begin{array}{ll}\% & 83.9\end{array}\right)$

$\mathrm{Z}=\mathrm{S} \quad \mathrm{M}^{+} \cdot 154 \mathrm{gmol}^{-1}(\%$ 48.4)

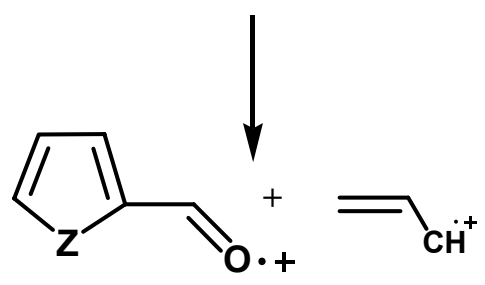

$\begin{array}{lll}\mathrm{Z}=\mathrm{O} & \mathrm{m} / \mathrm{z}: 97 & \mathrm{~m} / \mathrm{z}: 41 \\ \mathrm{Z}=\mathrm{S} & \mathrm{m} / \mathrm{z}: 112\end{array}$

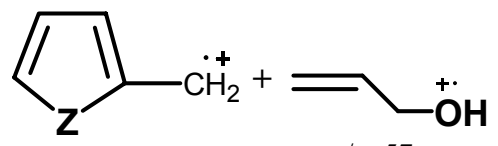

(base peak)

$\mathrm{Z}=\mathrm{O} \mathrm{m} / \mathrm{z}: 81$

$\mathrm{Z}=\mathrm{S} \mathrm{m} / \mathrm{z}: 97$
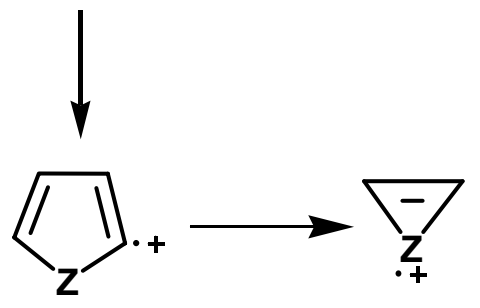

$\mathrm{Z}=\mathrm{O} \mathrm{m} / \mathrm{z}: 68$

$\mathrm{Z}=\mathrm{S} \mathrm{m} / \mathrm{z}: 83$ $\mathrm{m} / \mathrm{z}: 57$

$\mathrm{Z}=\mathrm{O} \mathrm{m} / \mathrm{z}: 41$

$\mathrm{Z}=\mathrm{S}: \mathrm{m} / \mathrm{z}: 58$

\section{Acknowledgments}

We are indebted to the Firat University Research Foundation (FÜNAF) for financial support of this work (Project number: 351 ) 


\section{Experimental}

\section{General}

The synthetic routes followed are outlined in Scheme 4. $\mathrm{CrCl}_{2}, \mathrm{CrCl}_{3}, \mathrm{LiAlH}_{4}, \mathrm{DMF}$, THF, vinyl bromide, allyl bromide, furan-2-carboxaldehyde, thiophene-2-carboxaldehyde and n-BuLi were obtained from commercial sources and all the solvents were used without further purification. The products were purified by column chromatography using one of the following eluent systems: (A) 6:1 hexane-ethyl acetate; (B) 4:1 hexane-ethyl acetate; (C): 5:1:1 hexane-ethyl acetate-acetone. IR spectra $(\mathrm{NaCl}$, thin film) were measured on a Mattson series FT-IR 1000 model spectrometer and ${ }^{1} \mathrm{H}-\mathrm{NMR}$ spectra were measured on a JEOL FX-90 Q instrument at 90 $\mathrm{MHz}$, using $\mathrm{CDCl}_{3}$ as solvent. Shift values are reported in ppm relative to TMS. GC/MS (eV, EI) analysis measurement on a Micromass Zabspec model instrument was determined at The Scientific and Technical Research Council of Turkey (TUBITAK).

\section{Scheme 4}

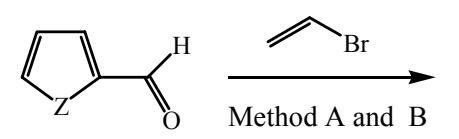

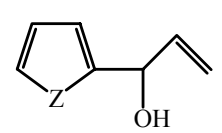

1,2
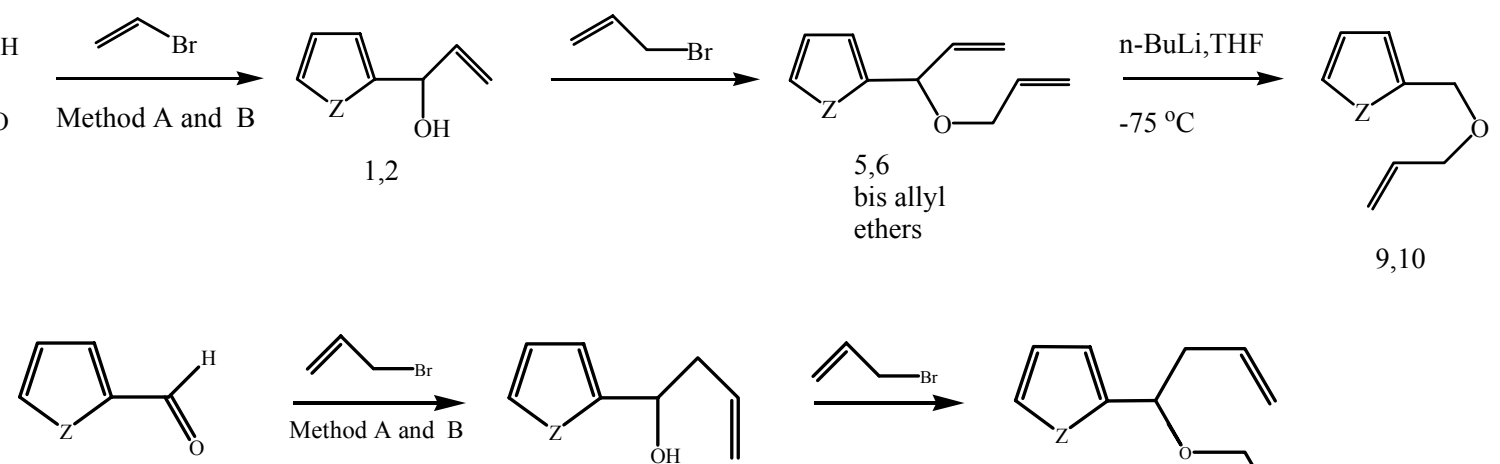

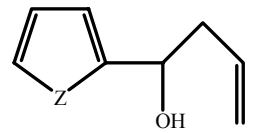

3,4
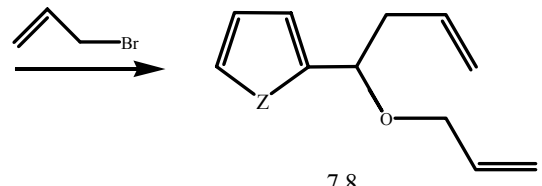

homo allyl ethers

$Z=O$ for compounds $1,3,5,7,9$ and $Z=S$ for compounds $2,4,6,8,10$

Addition of Organochromium Reagents to Heteroaromatic Aldehydes: Synthesis of Heteroaromatic Substituted Allyl Alcohols $(\mathbf{1}, \mathbf{2})$ and Homoallyl Alcohols $(\mathbf{3}, \mathbf{4})$

\section{Method A:}

Solutions of vinyl bromide $(4.0 \mathrm{mmol})$ in DMF $(10 \mathrm{~mL})$ and heteroaromatic aldehyde $(2.0$ mmol $)$ in DMF $(6 \mathrm{~mL})$ were added at $25^{\circ} \mathrm{C}$ to a stirred suspension of $\mathrm{CrCl}_{2}(0.98 \mathrm{gr}, 8.0 \mathrm{mmol})$ in DMF $(8 \mathrm{~mL})$ over a period of $10 \mathrm{~min}$ under an argon atmosphere. After being stirred at $25{ }^{\circ} \mathrm{C}$ for $15 \mathrm{~min}$, the mixture was quenched by addition of water $(20 \mathrm{~mL})$ and extracted with ether. The reaction mixture was filtered, the residues were washed with twice with ether, dried with $\mathrm{MgSO}_{4}$ and concentrated under vacuum to give the crude product that was purified by column chromatography over silica gel. 


\section{Method B:}

$\mathrm{CrCl}_{3}$ (4,28 gr, $\left.27 \mathrm{mmol}\right)$ was reduced with $\mathrm{LiAlH}_{4}(513 \mathrm{mg}, 13.5 \mathrm{mmol})$ in THF $(20 \mathrm{~mL})$. After stirring at room temperature for $10 \mathrm{~min}$, the heteroaromatic aldehyde $(6.1 \mathrm{mmol})$ and subsequently vinyl bromide $(13.5 \mathrm{mmol})$ in THF $(10 \mathrm{~mL})$ were added dropwise over a period of $20 \mathrm{~min}$. After stirring for $3 \mathrm{~h}$ and extracting with ether the reaction mixture was filtered, the residues were washed with twice with ether, dried with $\mathrm{MgSO}_{4}$ and concentrated under vacuum give the crude product that was purified by column chromatography over silica gel.

1-(2-furyl) propen-1-ol (1): Yield: 81.3\% (Method A), 76 \%; (Method B) Rf: 0.652 (eluent system A); IR (KBr): 3706-3166, 3117, $1667 \mathrm{~cm}^{-1} .{ }^{1} \mathrm{H}-\mathrm{NMR}: \delta 2.85$ (broad, $\left.\mathrm{OH}, 1 \mathrm{H}\right), 4.84(\mathrm{~s}, \mathrm{CH}, 1 \mathrm{H})$, 5.10-6.20 (m, $\left.\mathrm{CH}=\mathrm{CH}_{2}, 3 \mathrm{H}\right), 6.62-7.67$ ( $\mathrm{m}$, furan ring protons, $\left.3 \mathrm{H}\right)$

1-(2-thienyl) propen-1-ol (2): Yield: $85.2 \%$ (Method A), $74.9 \%$; (Method B); Rf: 0.543 (eluent system A); IR (KBr): 3693-3128, 3104, $1641 \mathrm{~cm}^{-1} .{ }^{1} \mathrm{H}-\mathrm{NMR}: \delta 3.01$ (broad, OH, 1H), 4.71 (s, $\mathrm{CH}, 1 \mathrm{H}), 5.40-6.44\left(\mathrm{~m}, \mathrm{CH}=\mathrm{CH}_{2}, 3 \mathrm{H}\right), 6.66-7.21$ (m, thiophene ring protons, $\left.3 \mathrm{H}\right)$

1-(2-furyl)-3-buten-1-ol (3): Yield: 75.7 \% (Method A), $61.9 \%$; (Method B); Rf: 0.611 (eluent system B); IR (KBr): 3743-3148, 3078, $1643 \mathrm{~cm}^{-1} .{ }^{1} \mathrm{H}-\mathrm{NMR}: \delta$ 1.60-1.95 (m, $\left.\mathrm{CH}_{2}, 2 \mathrm{H}\right), 2.57$ (broad, $\mathrm{OH}, 1 \mathrm{H}), 3.68(\mathrm{t}, \mathrm{CH}, 1 \mathrm{H}), 4.45-5.25\left(\mathrm{~m}, \mathrm{CH}=\mathrm{CH}_{2}, 3 \mathrm{H}\right), 6.23$ and 7.33 (furan ring protons, $3 \mathrm{H}$ )

1-(2-thienyl)-3-buten-1-ol (4): Yield: $75.5 \%$ (Method A), 63.6\%; (Method B); Rf: 0.522 (eluent system B); IR (KBr): 3610-3175, 3076, $1650 \mathrm{~cm}^{-1} .{ }^{1} \mathrm{H}-\mathrm{NMR}: \delta 1.76-1.83\left(\mathrm{~m}, \mathrm{CH}_{2}, 2 \mathrm{H}\right), 2.85$ (broad, $\mathrm{OH}, 1 \mathrm{H}), 3.68(\mathrm{~s} \mathrm{CH}, 1 \mathrm{H}), 4.25-5.25\left(\mathrm{~m}, \mathrm{CH}=\mathrm{CH}_{2}, 3 \mathrm{H}\right), 6.52-7.73$ (m, thiophene ring protons, $3 \mathrm{H})$

General Procedure for the Synthesis of bis-Allyl Ethers and Homoallyl Ethers (5-8):

Allyl bromide $(17.0 \mathrm{~mL}, 220 \mathrm{mmol})$ or vinyl bromide $(220 \mathrm{mmol})$ in THF $(20 \mathrm{~mL})$ was added dropwise to a vigorously stirred mixture of heteroaromatic allylic alcohols (200 mmol), n- $\mathrm{Bu}_{4} \mathrm{NHSO}_{4}(3.7 \mathrm{gr}, 10 \mathrm{mmol}), \mathrm{NaOH}(16.0 \mathrm{gr}, 400 \mathrm{mmol})$ and $\mathrm{H}_{2} \mathrm{O}(4 \mathrm{~mL})$. The resulting mixture was stirred overnight at room temperature. The solid formed was filtered off. Usual work up followed by distillation afforded the title compounds.

2-(1-Allyloxy allyl) furan (5): Yield: $63.3 \%$; Rf: 0.719 (eluent system D); IR (KBr); 3146, 3119, 3080, 1072, 1661, $1153 \mathrm{~cm}^{-1} .{ }^{1} \mathrm{H}-\mathrm{NMR} \delta 3.85-4.10\left(\mathrm{CH}_{2}-\mathrm{O}, 2 \mathrm{H}\right), 4.44(\mathrm{~s}, \mathrm{CH}-\mathrm{O}, 1 \mathrm{H}), 5.05-6.00$ $\left(\mathrm{m}, \mathrm{CH}=\mathrm{CH}_{2}, 6 \mathrm{H}\right), 6.30$ and 7.39 (furan ring protons, $3 \mathrm{H}$ )

2-(1-Allyloxy allyl) thiophene (6): Yield: $71.0 \%$; Rf: 0.648 (eluent system C); IR (KBr); 3101, 3082, 1644, $1074 \mathrm{~cm}^{-1} .{ }^{1} \mathrm{H}-\mathrm{NMR}$ : $\delta 3.85-4.10\left(\mathrm{CH}_{2}-\mathrm{O}, 2 \mathrm{H}\right), 4.67$ (s, CH-O, 1H), 5.02-6.15 (m, $\left.\mathrm{CH}=\mathrm{CH}_{2}, 6 \mathrm{H}\right), 6.80-7.10$ (m, thiophene ring protons, $\left.3 \mathrm{H}\right)$ 
2-(1-Allyloxy-3-butenyl) furan (7): Yield: 51\%; Rf: 0.731 (eluent system A); IR (KBr); 3088, 3019, 1650, 1240, $1080 \mathrm{~cm}^{-1} .{ }^{1} \mathrm{H}-\mathrm{NMR}: \delta 3.65-4.10\left(\mathrm{~m}, \mathrm{CH}_{2}, 2 \mathrm{H}\right), 4.60-5.41\left(\mathrm{~m}, \mathrm{CH}-\mathrm{O}\right.$ and $\mathrm{CH}_{2}-$ $\mathrm{O}, 3 \mathrm{H}), 5.61-6.45\left(\mathrm{~m}, \mathrm{CH}=\mathrm{CH}_{2}, 6 \mathrm{H}\right), 7.15-7.55$ (m, furan ring protons, $3 \mathrm{H}$ )

2-(1-Allyloxy-3-butenyl) thiophene (8): Yield: $63.1 \%$; Rf: 0.633 (eluent system A); IR: 3105, 3078, 1648, 1228, $1080 \mathrm{~cm}^{-1} .{ }^{1} \mathrm{H}-\mathrm{NMR}: \delta 3.98-4.10\left(\mathrm{~m}, \mathrm{CH}_{2}, 2 \mathrm{H}\right), 4.50-4.65\left(\mathrm{~m}, \mathrm{CH}-\mathrm{O}\right.$ and $\mathrm{CH}_{2}-$ $\mathrm{O}, 3 \mathrm{H}), 4.90-6.11-\left(\mathrm{m}, \mathrm{CH}=\mathrm{CH}_{2}, 6 \mathrm{H}\right), 6.61-7.51$ (m, thiophene ring protons, $\left.3 \mathrm{H}\right)$

2-Allyloxymethyl furan (9) and 2-allyloxymethyl thiophene (10) were synthesized via [2,3]Wittig rearrangement reactions of the unsymmetrical bis-allyl ethers under an argon atmosphere and at $-75^{\circ} \mathrm{C}$ in high yields according to literature methods [6-10].

2-Allyloxymethyl furan (9): Yield: $57.2 \%$; Rf: 0.544 (eluent system C); IR (KBr); 3146, 3119, 3080, 1068, 1663, $1157 \mathrm{~cm}^{-1}$. ${ }^{1} \mathrm{H}-\mathrm{NMR}: \delta 4.10$ (s, $\left.\mathrm{CH}_{2}-\mathrm{O}, 2 \mathrm{H}\right), 4.85$ (s, $\left.\mathrm{CH}_{2}-\mathrm{O}, 2 \mathrm{H}\right), 5.21-5.89$ $\left(\mathrm{m}, \mathrm{CH}=\mathrm{CH}_{2}, 3 \mathrm{H}\right.$ ), 6.23 and 7.33 (furan ring protons, $3 \mathrm{H}$ ); GC/MS: $\mathrm{M}^{+} \cdot 138$, base peak: 81 , retention time: $16.96 \mathrm{~min}$.

2-Allyloxymethyl thiophene (10): Yield: $61.4 \%$; Rf: 0.503 (eluent system C); IR (KBr); 3101, 3082, 1641, $1072 \mathrm{~cm}^{-1} .{ }^{1} \mathrm{H}-\mathrm{NMR}: \delta 4.13$ (s, $\left.\mathrm{CH}_{2}-\mathrm{O}, 2 \mathrm{H}\right), 4.63$ (s, $\left.\mathrm{CH}_{2}-\mathrm{O}, 2 \mathrm{H}\right)$, 5.17-6.09 (m, $\mathrm{CH}=\mathrm{CH}_{2}, 3 \mathrm{H}$ ), 6.73-7.10 (m, thiophene ring protons, $3 \mathrm{H}$ ); GC/MS: $\mathrm{M}^{+} \cdot 154$, base peak: 97 , retention time: $21.94 \mathrm{~min}$.

\section{References}

1. Okude, Y.; Hirano, S.; Hiyama, T.; Nozaki, H. Grignard-type carbonyl addition of allyl halides by means of chromous salt chemospecific synthesis of homoallyl alcohols. J. Am. Chem. Soc. 1977, 99, 3179-3181.

2. Takai, K.; Kimura, K.; Kuroda, T.; Hiyama, T.; Nozaki, H. Selective Grignard type carbonyl addition of alkenyl halides mediated by chromium (II) chloride. Tetrahedron Lett. 1983, 24, 5281-5284.

3. Cintos, P. Addition of organochromium compounds to aldehyde: Nozaki-Hiyama reaction. Synthesis 1992, 248-257.

4. Furstner, A. Carbon-carbon bond formations involving organochromium (III) reagents Chem. Rev. 1999, 99, 991-1045

5. Wuts, P.G.M.; Callen, G.R. An improved procedure for the $\mathrm{Cr}$ (II) mediated homoallylic alcohol synthesis. Synth. Commun. 1986, 16, 1833-1837

6. Servi, S.; Acar, A. An investigation of the reactions of substituted homoallylic alcohols with various oxidation reagents. Molecules 2002, 7, 104-111.

7. Nakai, T.; Mikami, K. [2,3]-Wittig sigmatropic rearrangements in organic synthesis. Chem. Rev. 1986, 86, 885-902.

8. Mikami K.; Nakai T. Applications of the tandem [2,3]-Wittig oxy-Cope rearrangement to synthesis of exo-brevicomin and oxocrinol. The scope and limitation of the sigmatropic 
sequences as a synthetic method for delta, epsilon-unsaturated ketones. Chem. Lett. 1982, 9, 1349-1352.

9. Mikami, K.; Kishi, N.; Nakai, T. New sigmatropic sequences based on the [2,3]-Wittig rearrangement of the bis-allylic ether system. Tetrahedron 1986, 42, 2911-2918.

10. Nicholas G.; Wai-Man L. Stereoselective [2,3]-Wittig and tandem [2,3]-Wittig anionic oxycope rearrangement of bis allylic ethers: effect of substituents. Tetrahedron Lett. 1997, 38, 6445-6448,

11. Zair, T.; Santelli, C.; Santelli, R.M. Palladium mediated cyclization of 1,5-hexadien-3-ols to 1-methyl-1,3-cyclopentadienes. Tetrahedron 1993, 49, 3313-3324.

12. Servi, S.; Ahmetzade, M.; Coskun, M.; Cansiz, A. Use of 2-alkenyl-3-(chloromethyl) oxiranes in the synthesis of 1, 5-dien-3-ols. S. Afr. J. Chem. 2000, 53, 73-76.

13. Servi, S.; Digrak, M.; Cansiz, A.; Ahmetzade, M. Synthesis of allyl-cyclopropyl alcohols and allyl-1,5-hexadien-3-ols and investigation of their antibacterial and antifungal activities. Ind. J. Chem. 2000, 39, 629-633.

14. Budzikiewicz, H.; Djerassi, C.; Williams, H.D. Ethers, acetals, ketals, and orthoesters, Mass Spectrometry of Organic Compounds; Holden-Day Inc.: San Francisco, California, USA 1967; pp. $232-233$

Sample Availability: Available from the authors.

2004 by MDPI (http://www.mdpi.org). Reproduction is permitted for noncommercial purposes. 